\title{
Cystic Duct Metastasis from Renal Cell Carcinoma
}

\author{
Hideaki Koga ${ }^{1}$, Kei Yane ${ }^{1}$, Hiroyuki Maguchi ${ }^{1}$, Kuniyuki Takahashi ${ }^{1}$, Akio Katanuma ${ }^{1}$, \\ Toshifumi Kin ${ }^{1}$, Yoshiyasu Ambo ${ }^{2}$, Yuko Omori ${ }^{3}$ and Toshiya Shinohara ${ }^{3}$
}

\begin{abstract}
:
We herein report a 69-year-old man who underwent right nephrectomy 1 year previously to remove renal cell carcinoma (RCC). On our examinations, contrast-enhanced computed tomography revealed a tumor with intensive early enhancement near the cystic duct of the gallbladder. Endoscopic ultrasonography showed a low echoic mass in the cystic duct. We diagnosed the patient's condition as cystic duct metastasis from RCC and performed open cholecystectomy. Histopathology indicated a metastatic tumor of clear cell RCC in the cystic duct wall. In patients with a medical history of RCC, hypervascular lesions suggest the possibility of metastasis. Therefore, detailed imaging examinations should be performed.
\end{abstract}

Key words: cystic duct, renal cell carcinoma, metastasis, gallbladder, EUS, imaging findings

(Intern Med 57: 213-218, 2018)

(DOI: 10.2169/internalmedicine.9228-17)

\section{Introduction}

Renal cell carcinoma (RCC) represents $2-3 \%$ of all cancers and accounts for approximately $90 \%$ of all kidney malignancies (1). One-third of patients have metastatic disease at the initial presentation; however, gallbladder metastasis from RCC is rare, and only few cases have been reported (2-5). To our knowledge, cystic duct metastasis from $\mathrm{RCC}$ has never been reported.

We herein report an extremely rare case of cystic duct metastasis from RCC preoperatively diagnosed in a patient. We also discuss its imaging and pathological characteristics, as well as its mechanism and treatment.

\section{Case Report}

A 69-year-old man visited our hospital for the evaluation of a cystic lesion in the pancreatic head that had bene found during a routine health checkup. One year previously, he had undergone right nephrectomy to remove clear cell RCC. Histology of the resected specimen showed slight vessel invasion, but no lymphatic vessel invasion. The postoperative staging was T2, N0, Stage II according to the Union for International Cancer Control (7th edition). His recent physical examination findings were unremarkable, although his blood examination revealed slight elevation in his creatinine level (Table 1). Computed tomography (CT) and magnetic resonance cholangiopancreatography (MRCP) showed multilocular cysts connecting with the main pancreatic duct, so the cystic lesion was diagnosed as a branch duct type intraductal papillary mucinous neoplasm. However, an oval tumor was found coincidently near the cystic duct, prompting us to perform detailed imaging examinations.

Abdominal ultrasonography (US) showed a smooth marginated mass with a homogeneous echo pattern near the cystic duct and a swollen gallbladder with stones (Fig. 1). Contrast-enhanced CT revealed the presence of a 13-mmdiameter tumor with intensive early enhancement located near the cystic duct (Fig. 2). On magnetic resonance imaging, the tumor showed a low signal intensity on T1weighted images and a high signal intensity on T2-weighted images compared with the normal liver parenchyma. On diffusion-weighted imaging, the tumor showed a high signal intensity, and the apparent diffusion coefficient value was $1.5 \times 10^{-3} \mathrm{~mm}^{2} / \mathrm{s}$. MRCP showed a smooth signal defect in the cystic duct (Fig. 3). Endoscopic ultrasonography showed a well-circumscribed, oval, low-echoic mass surrounded by a cystic duct wall, suggesting the presence of a tumor in the cystic duct (Fig. 4). Endoscopic retrograde cholangiography

${ }^{1}$ Center for Gastroenterology, Teine-Keijinkai Hospital, Japan, ${ }^{2}$ Department of Surgery, Teine-Keijinkai Hospital, Japan and ${ }^{3}$ Department of Pathology, Teine-Keijinkai Hospital, Japan

Received: March 22, 2017; Accepted: April 20, 2017; Advance Publication by J-STAGE: November 1, 2017

Correspondence to Dr. Hideaki Koga, kogahideaki00@gmail.com 
Table 1. Laboratory Data on Admission.

\begin{tabular}{|c|c|c|c|c|c|}
\hline \multicolumn{2}{|c|}{ Complete blood count } & \multirow{2}{*}{$\begin{array}{c}\text { Reference ranges } \\
3,500-9,400\end{array}$} & \multicolumn{2}{|l|}{ Blood chemistry } & \multirow{2}{*}{$\begin{array}{c}\text { Reference ranges } \\
0.2-1.0\end{array}$} \\
\hline $\mathrm{WBC}(/ \mu \mathrm{L})$ & 3,510 & & Total bilirubin (mg/dL) & 0.7 & \\
\hline $\mathrm{RBC}\left(\times 10^{4} / \mu \mathrm{L}\right)$ & 442 & $420-570$ & AST (IU/L) & 24 & $10-38$ \\
\hline Hemoglobin (g/dL) & 14.1 & $13-17.5$ & ALT (IU/L) & 23 & $6-38$ \\
\hline Hematocrit (\%) & 40.1 & $39.8-51.8$ & $\operatorname{ALP}(\mathrm{IU} / \mathrm{L})$ & 295 & $110-390$ \\
\hline \multirow[t]{2}{*}{ Platelet $\left(\times 10^{4} / \mu \mathrm{L}\right)$} & 11.4 & $13.0-38.0$ & $\gamma$-GTP (IU/L) & 21 & $7-70$ \\
\hline & & & LDH (IU/L) & 161 & $115-255$ \\
\hline \multicolumn{2}{|c|}{ Tumor marker } & & Amylase (IU/L) & 101 & $40-126$ \\
\hline \multirow{9}{*}{$\begin{array}{l}\text { CEA }(\mathrm{ng} / \mathrm{mL}) \\
\text { CA 19-9 }(\mathrm{U} / \mathrm{mL})\end{array}$} & 2.3 & $<10$ & Sodium $(\mathrm{mEq} / \mathrm{L})$ & 142 & 136-147 \\
\hline & 19.6 & $<37$ & Potassium (mEq/L) & 4.3 & $3.5-5.0$ \\
\hline & & & Chloride $(\mathrm{mEq} / \mathrm{L})$ & 109 & $95-110$ \\
\hline & & & Total protein $(\mathrm{g} / \mathrm{dL})$ & 5.8 & $6.3-8.5$ \\
\hline & & & Albumin (g/dL) & 4.0 & $3.3-5.1$ \\
\hline & & & BUN (mg/dL) & 25.3 & $7-22$ \\
\hline & & & Creatinine $(\mathrm{mg} / \mathrm{dL})$ & 1.18 & $0.61-1.10$ \\
\hline & & & Blood sugar (mg/dL) & 97 & $70-110$ \\
\hline & & & CRP (mg/dL) & 0.79 & $<0.20$ \\
\hline
\end{tabular}

WBC: white blood cell count, RBC: red blood cell count, CEA: carcinoembryonic antigen, CA 19-9: cancer antigen 19-9, AST: aspartate aminotransferase, ALT: alanine aminotransferase, ALP: alkaline phosphatase, $\gamma$-GTP: gammaglutamyl transpeptidase, LDH: lactate dehydrogenase, BUN: blood urea nitrogen, CRP: C-reactive protein

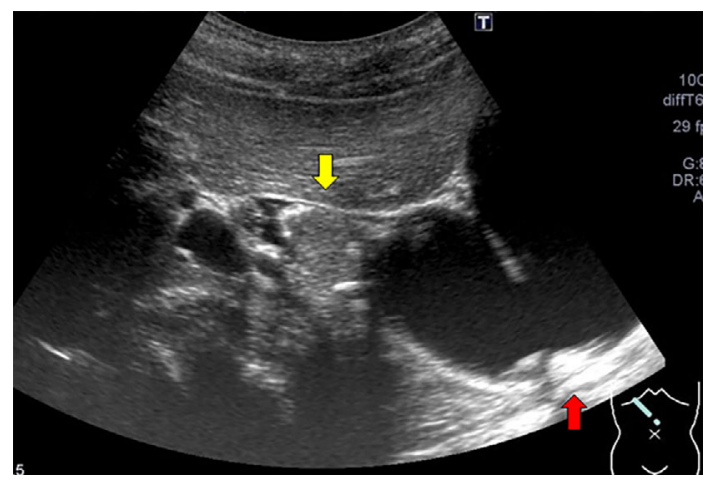

Figure 1. Abdominal ultrasonography showing a smooth marginated mass with a homogeneous echo pattern near the cystic duct (yellow arrow) and a swollen gallbladder with stones (red arrow).

showed a smooth defect in the cystic duct and displacement of the common bile duct from the gallbladder side (Fig. 5). Although a biopsy using a peroral cholangioscope (POCS) was attempted to establish a pathological diagnosis, the biopsy could not be performed because the POCS could not pass through the cystic duct. These imaging findings indicated the presence of a tumor in the cystic duct wall. Endoscopic ultrasonography (EUS)-guided fine needle aspiration was not performed due to the risk of bile leakage and tumor bleeding and seeding. Based on these imaging findings, we diagnosed the patient's condition as cystic duct metastasis from RCC. As other metastatic sites were not observed, open cholecystectomy was performed.

Histopathology showed a $13 \times 11-\mathrm{mm}$ solid metastatic tumor of clear cell RCC in the cystic duct wall. The tumor had an alveolar architecture of cells with a clear or eosinophilic cytoplasm, separated by a delicate branching network of vascular tissue. A normal epithelium remained in some part of the tumor surface. The tumor was present in the lamina propria of the cystic duct and was elevated towards the mucosal side, resembling a polypoid lesion (Fig. 6). There was no lymph node component at the peripheral lesion. Immunohistochemistry showed tumor cell expressions of AE1/ $\mathrm{AE} 3, \mathrm{CD} 10$, and vimentin, which were consistent with the diagnosis of metastatic clear cell RCC. The histopathological and immunohistochemical staining results of the cystic duct metastasis were the same as those of the primary kidney cancer.

There were no operation-related adverse events, and the patient was followed up without adjuvant therapy in an outpatient clinic. He remained disease-free until seven months of follow-up.

\section{Discussion}

RCC has a high metastatic potential. Indeed, one-third of patients present with metastatic disease at the diagnosis (6). In addition, up to $50 \%$ develop metastatic disease metachronously after surgical resection. The most common sites of distant metastasis are the lung, bone, liver, adrenal gland, brain, and contralateral kidney $(2,3)$. RCC metastasis to the gallbladder is rare and has only been found in $0.58 \%$ of cases at necropsy (7). Neves et al. reported a review of 52 patients published in the English and Japanese literature (3). Metachronous gallbladder metastasis was found in $69.2 \%$ of patients with a median disease-free interval from nephrectomy of 4 years. Clear cell type was identified in $97.4 \%$ of patients, and polypoid lesions were observed in $92 \%$ of patients.

Cancer metastasis to the cystic duct is extremely rare, and only three cases have been reported thus far in the literature 

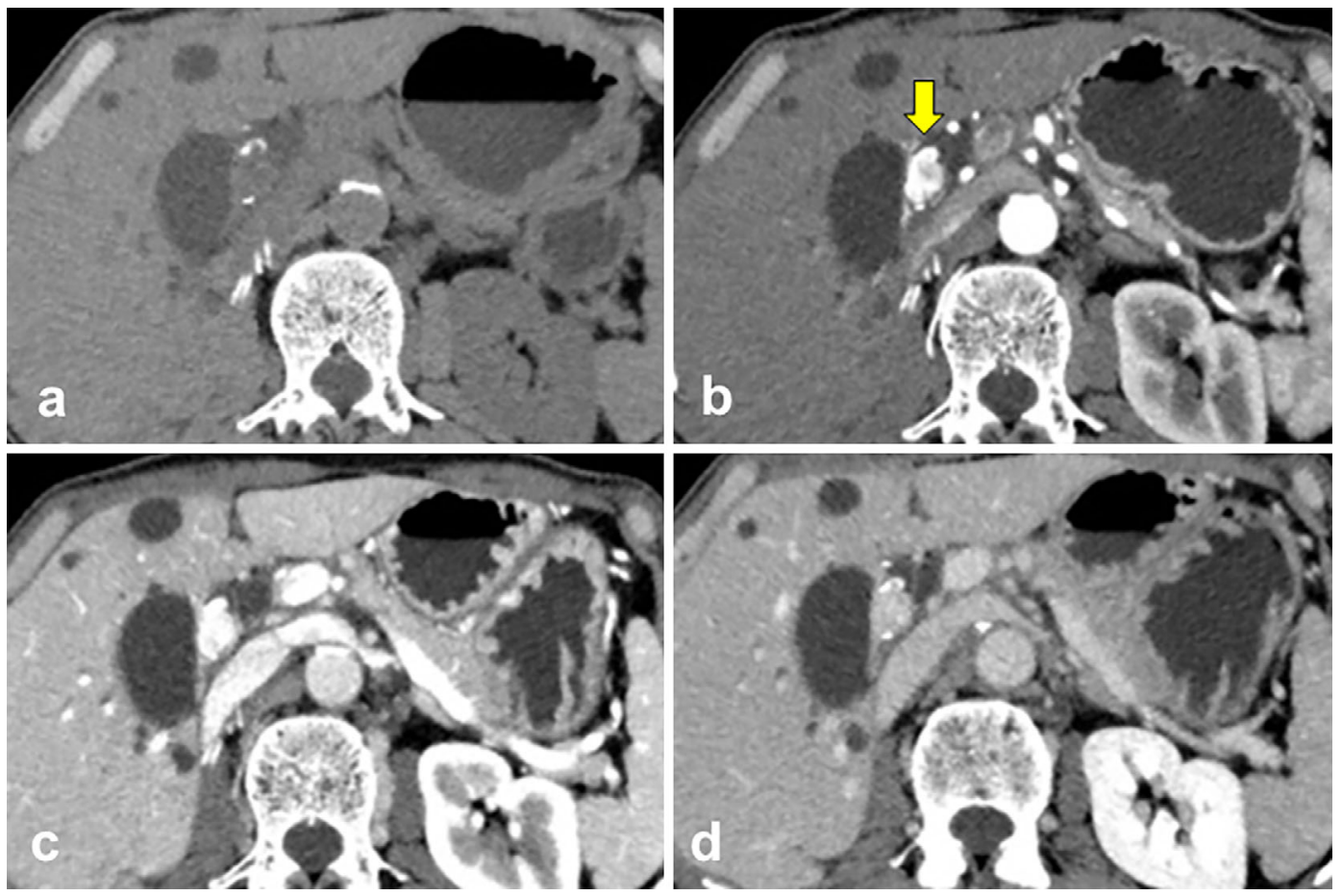

Figure 2. Contrast-enhanced computed tomography showing the presence of a 13-mm diameter tumor with intensive early enhancement located near the cystic duct (yellow arrow). a. Plain. b. Arterial phase. c. Portal venous phase. d. Delayed phase.

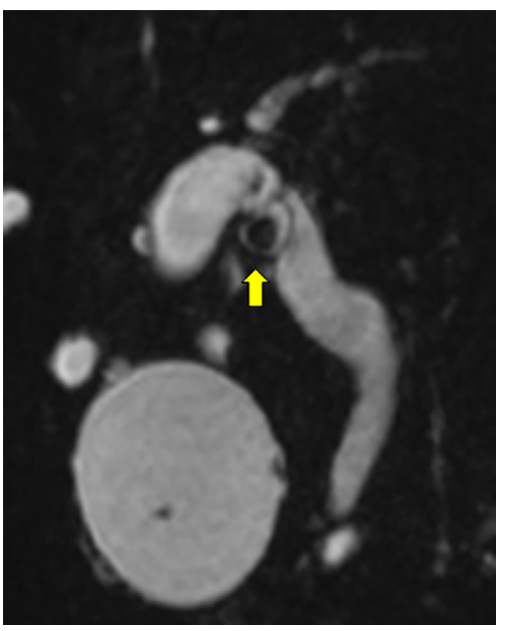

Figure 3. Magnetic resonance cholangiopancreatography showing a smooth signal defect in the cystic duct (yellow arrow).

(Table 2). Two of these cases were cystic duct metastasis from breast cancer. Cholecystectomy was performed for acute acalculous cholecystitis, and a histopathological examination led to an unexpected diagnosis of cystic duct metastasis $(8,9)$. The other case was that of a patient with cystic duct metastasis from rectal cancer that was diagnosed incidentally during surgery for rectal cancer and liver metastasis (10). All three cases were unable to be diagnosed as cystic duct metastasis of the cancer by imaging examinations before surgical resection.

Regarding the imaging features of metastatic gallbladder cancer, a polypoid tumor with intensive early enhancement was detected on contrast-enhanced CT, and a smooth marginated lesion with a superficial hyperechoic band was noted on US $(4,5)$. In the present case, the smooth marginated cystic duct tumor showed intensive early enhancement, so the patient was able to be diagnosed preoperatively with cystic duct metastasis from RCC.

Cancer metastasis is considered to result from hematogenous, lymphatic, disseminated, and direct invasion. Cancer often metastasizes hematogenously to the lamina propria of the gallbladder wall (10), and gallbladder metastasis shows characteristic polypoid lesions (3). We consider that cancer that has metastasized to the lamina propria of the gallbladder wall can spread easily to the mucosal side because the muscularis propria is located under the lamina propria. Therefore, metastatic tumors of the gallbladder show polypoid lesions. In the present case, the cystic duct tumor was also present in the lamina propria and showed polypoid growth, as reported previously $(3,10)$. RCC has a high potential for hematogenous metastasis, and the most common metastatic sites are vascular-rich organs. In addition, the frequency of lymph node metastasis from RCC is low in cases without other organ metastasis (11). In the present case, imaging examinations revealed no metastatic tumors, except for in the cystic duct. The primary lesion did not have lymphatic vessel invasion. Furthermore, histopathological findings revealed that the tumor was present in the lamina propria of the cystic duct without any lymph node component around the tumor. Therefore, hematogenous metastasis to the cystic duct occurred. 

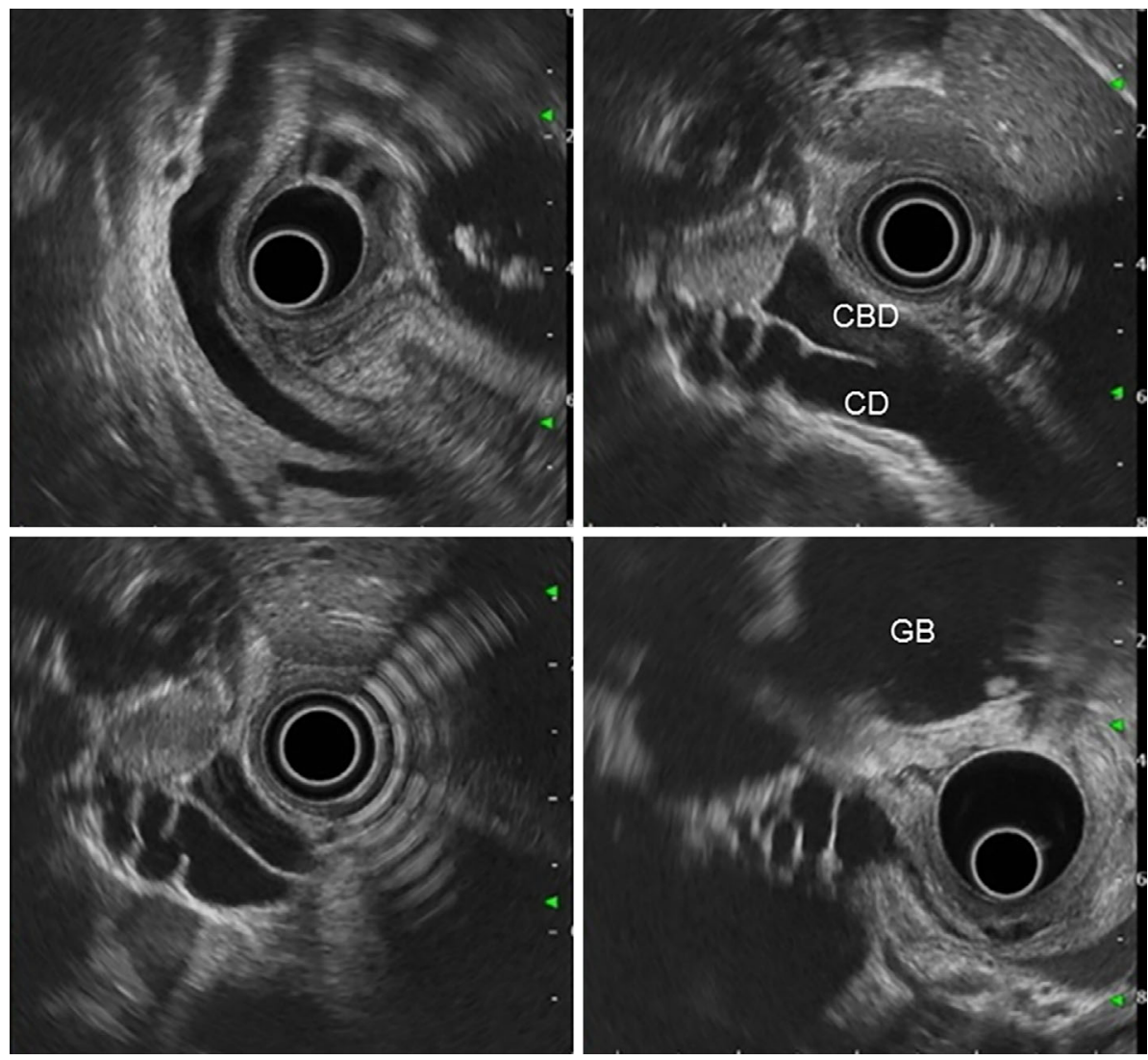

Figure 4. Endoscopic ultrasonography showing a well-circumscribed, oval, low-echoic mass surrounded by a cystic duct wall, suggesting the presence of the tumor in the cystic duct. CBD: common bile duct, CD: cystic duct, GB: gallbladder
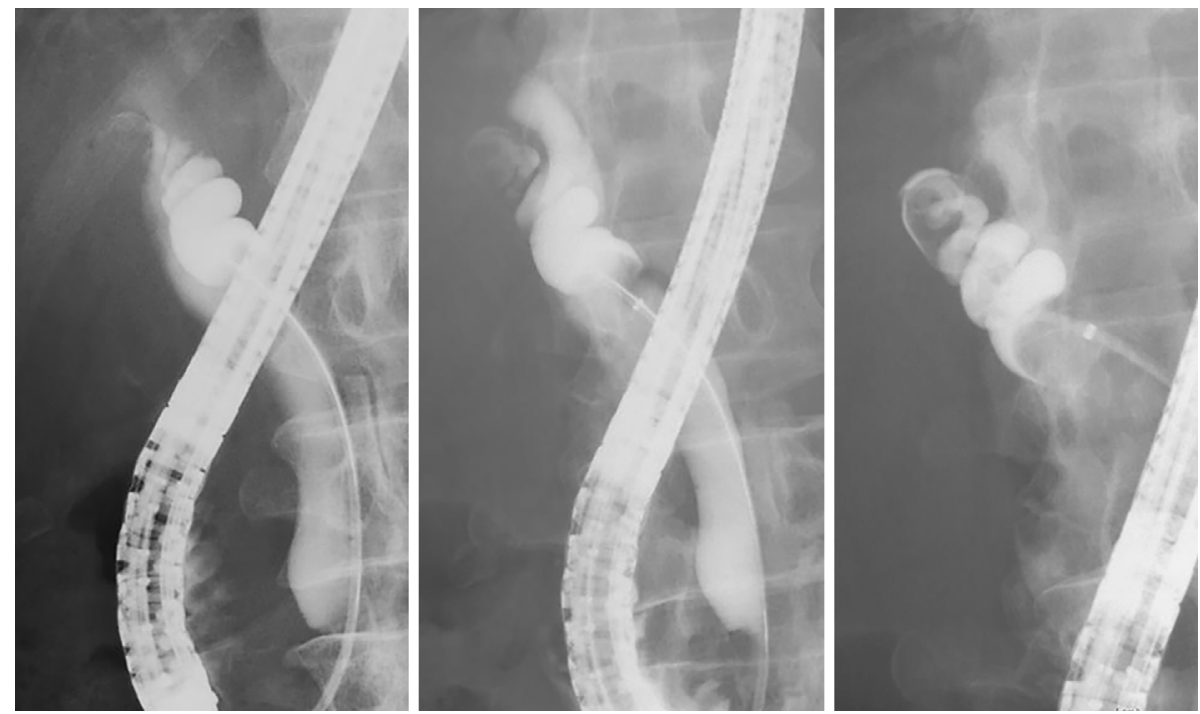

Figure 5. Endoscopic retrograde cholangiography showing a smooth defect in the cystic duct and the displacement of the common bile duct from the gallbladder side.

Surgical resection is a curative treatment for RCC only if all of the tumor burden can be removed. Metastasectomy may be justified in select patients with local metastatic disease. A systematic review reported that complete metastasectomy in any organs except the brain and bone benefited metastatic RCC patients in terms of their survival and delaying systemic therapy (12). In patients with metastatic clear cell RCC, chemotherapy has been shown to have little or no efficacy (13). A number of targeted agents have recently become available (14). However, there is still no evidence to support the use of adjuvant therapy after RCC surgery (14-16). Thus, cholecystectomy and careful follow-up 


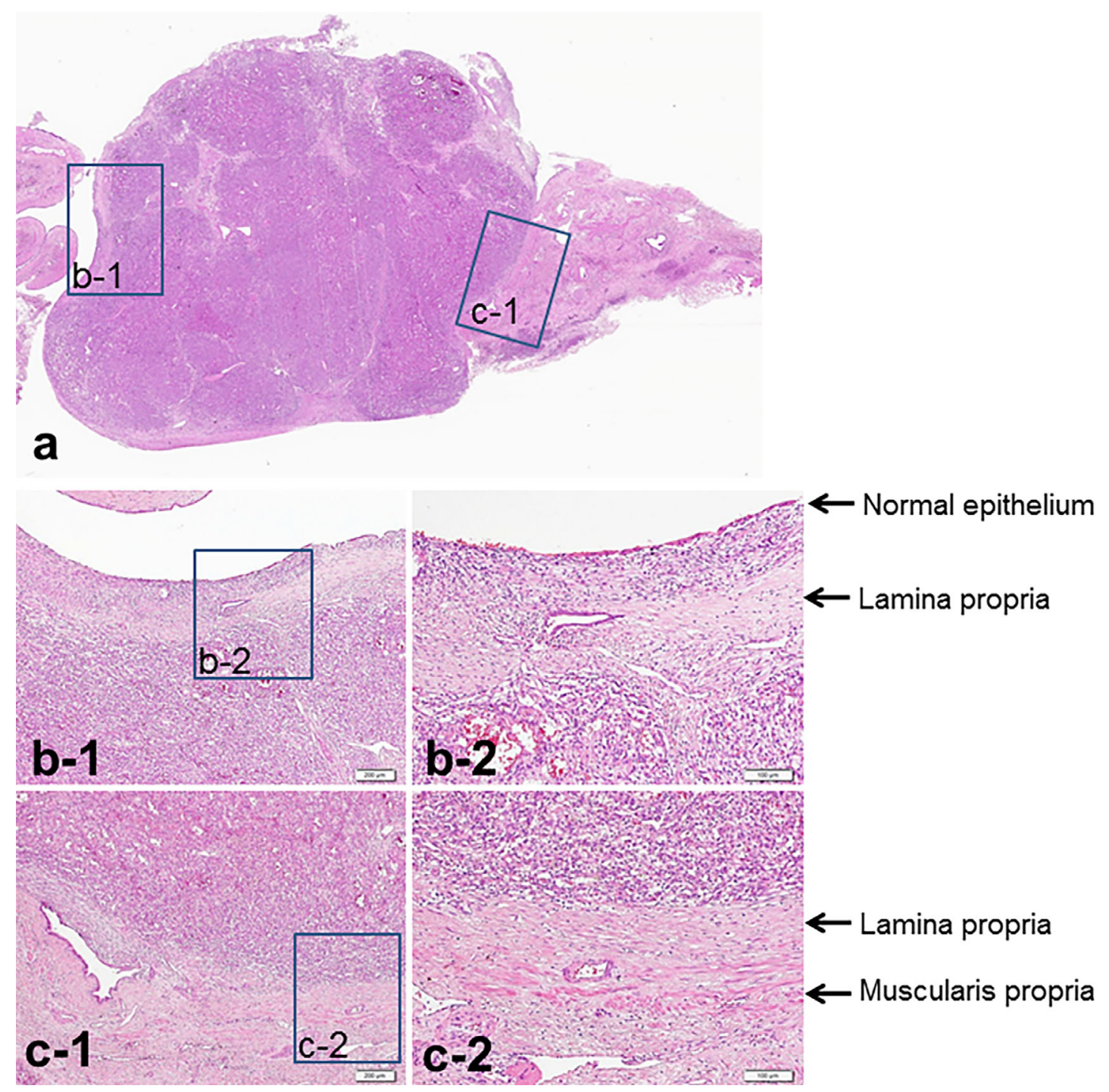

Figure 6. Histopathological findings (hematoxylin and eosin staining). a. $13 \times 11 \mathrm{~mm}$ solid metastatic tumor of clear cell RCC in the cystic duct wall. b. Normal epithelium remained on part of the tumor surface. $c$. The tumor was present in the lamina propria of the cystic duct and elevated towards the mucosal side.

Table 2. Summary of Cancer Metastasis to the Cystic Duct.

\begin{tabular}{|c|c|c|c|c|c|c|c|c|}
\hline & Reference & $\begin{array}{c}\text { Age } \\
\text { (years) }\end{array}$ & Sex & $\begin{array}{l}\text { Primary } \\
\text { cancer }\end{array}$ & $\begin{array}{l}\text { Opportunity } \\
\text { for diagnosis }\end{array}$ & Operation & $\begin{array}{c}\text { Macroscopic } \\
\text { appearance }\end{array}$ & $\begin{array}{c}\text { Other } \\
\text { metastasis }\end{array}$ \\
\hline 1 & 8 & 59 & $\mathrm{~F}$ & Breast & $\begin{array}{l}\text { Acalculous } \\
\text { cholecystitis }\end{array}$ & Cholecystectomy & polypoid & None \\
\hline 2 & 9 & 73 & $\mathrm{~F}$ & Breast & $\begin{array}{l}\text { Acalculous } \\
\text { cholecystitis }\end{array}$ & Cholecystectomy & Mass & $\begin{array}{l}\text { Lymph node } \\
\text { Liver }\end{array}$ \\
\hline 3 & 10 & 67 & M & Rectal & $\begin{array}{l}\text { Intraoperative } \\
\text { appearance }\end{array}$ & $\begin{array}{l}\text { Colon and liver } \\
\text { resection } \\
+ \text { Cholecystectomy }\end{array}$ & polypoid & Liver \\
\hline 4 & $\begin{array}{l}\text { Present } \\
\text { case }\end{array}$ & 69 & M & Kidney & $\begin{array}{l}\text { Preoperative } \\
\text { imaging } \\
\text { findings }\end{array}$ & Cholecystectomy & polypoid & None \\
\hline
\end{tabular}

without adjuvant therapy were considered adequate treatment for this patient.

In conclusion, we encountered an extremely rare case of cystic duct metastasis from RCC. This cystic duct tumor showed the characteristics of hematogenous metastasis to the gallbladder-namely hypervascularity and polypoid growth. In patients with a medical history of RCC, the presence of a hypervascular lesion suggests the possibility of metastasis 
from RCC. Therefore, detailed imaging examinations should be performed to definitively identify the lesion site and determine the optimal treatment strategy.

The authors state that they have no Conflict of Interest (COI).

\section{References}

1. Ljungburg B, Bensalah K, Canfield S, et al. EAU Guidelines on renal cell carcinoma: 2014 update. Eur Urol 67: 913-924, 2015.

2. Chung PH, Srinivasan R, Linehan WM, Pinto PA, Bratslavsky G. Renal cell carcinoma with metastases to the gallbladder: four cases from the National Cancer Institute (NCI) and review of the literature. Urol Oncol 30: 476-481, 2012.

3. Neves MC, Neofytou K, Giakoustidis A, et al. Two cases of gallbladder metastasis from renal cell carcinoma and review of literature. World J Surg Oncol 14: 87, 2016.

4. Ueda I, Aoki T, Oki H, et al. Gallbladder metastasis from renal cell carcinoma: a case report with review of the literature. Magn Reson Med Sci 14: 133-138, 2015.

5. Taniguchi K, Hayashi K, Oomori T, et al. A case of gallbladder metastasis from renal cell carcinoma. Nihon Rinsho Geka Gakkai Zasshi (J Jpn Surg Assoc) 74: 1024-1028, 2013 (in Japanese, Abstract in English).

6. Gupta K, Miller JD, Li JZ, Russell MW, Charbonneau C. Epidemiologic and socioeconomic burden of metastatic renal cell carcinoma (mRCC): a literature review. Cancer Treat Rev 34: 193-205, 2008.

7. Weiss L, Harlos JP, Torhorst J, et al. Metastatic patterns of renal carcinoma: an analysis of 687 necropsies. J Cancer Res Clin Oncol 114: 605-612, 1988.

8. Hashimoto M, Koide K, Arita M, et al. Acute acalculous cholecys- titis due to breast cancer metastasis to the cystic duct. Surg Case Rep 2: 111, 2016.

9. Andry G, Turnbull AD, Botet J, Kurtz RC. Cholesonographic characteristics of cystic duct metastasis causing acute acalculous cholecystitis: case report. J Surg Oncol 31: 178-181, 1986.

10. Wakahara T, Tsukamoto T, Toyokawa A, Iwasaki T, Hamabe Y, Teramura K. A case of cystic duct metastasis from rectal cancer. Nihon Shokakibyo Gakkai Zasshi (Journal of Japanese Society of Gastroenterology) 108: 2023-2029, 2011 (in Japanese, Abstract in English).

11. Saito H. Distant metastasis of renal adenocarcinoma. Cancer 48 : 1487-1491, 1981.

12. Dabestani S, Marconi L, Hofmann F, et al. Local treatments for metastases of renal cell carcinoma: a systematic review. Lancet Oncol 15: e549-e561, 2014.

13. Yagoda A, Abi-Rached B, Petrylak D. Chemotherapy for advanced renal-cell carcinoma: 1983-1993. Semin Oncol 22: 42-60, 1995.

14. Pal SK, Haas NB. Adjuvant therapy for renal cell carcinoma: past, present, and future. Oncologist 19: 851-859, 2014.

15. Pal SK, Williams S, Josephson DY, Carmichael C, Vogelzang NJ, Quinn DI. Novel therapies for metastatic renal cell carcinoma: efforts to expand beyond the VEGF/mTOR signaling paradigm. Mol Cancer Ther 11: 526-537, 2012.

16. Massari F, Bria E, Maines F, et al. Adjuvant treatment for resected renal cell carcinoma: are all strategies equally negative? Potential implications for trial design with targeted agents. Clin Genitourin Cancer 11: 471-476, 2013.

The Internal Medicine is an Open Access article distributed under the Creative Commons Attribution-NonCommercial-NoDerivatives 4.0 International License. To view the details of this license, please visit (https://creativecommons.org/licenses/ by-nc-nd/4.0/).

(C) 2018 The Japanese Society of Internal Medicine Intern Med 57: 213-218, 2018 